\title{
Potential of PVA templated Silica Xerogels as Adsorbents for Rhodamine 6G
}

\author{
Tahira Pirzada and Syed Sakhawat Shah ${ }^{\dagger, *}$ \\ Department of Chemistry, Quaid-i-Azam University, Islamabad, 44000, Pakistan \\ ${ }^{\dagger}$ Department of Chemistry, Hazara University, Mansehra, Pakistan. \\ *E-mail: shah_sakhawat@yahoo.com
}

(Received June 21, 2011; Accepted November 16, 2011)

\begin{abstract}
PVA/silica hybrid xerogels were synthesized by sonohydrolysis of a mixture of 2-way catalyzed TEOS and water solution of PVA. PVA was successfully removed from the xerogels through calcination and its removal was confirmed through TGA analysis of the calcined gel. Microstructure of the gels was studied through SEM, XRD and FTIR. Nitrogen sorption studies were conducted to find out surface area of different samples. It was found out that the samples having PVA removed through calcinations have higher surface area $\left(411.64 \mathrm{~m}^{2} / \mathrm{g}\right)$ than the samples $\left(353.544 \mathrm{~m}^{2} / \mathrm{g}\right)$ synthesized without any PVA. Adsorption properties of these xerogels synthesized by using different ratios of components were studied by taking Rhodamine G6 as a model adsorbate. The experiments were conducted at room temperature $\left(25^{\circ} \mathrm{C}\right)$. UV visible spectroscopy was used to measure the concentration of the dye before and after adsorption. The adsorption data of Rhodamine G6 on PVA modified silica is described by the Freundlich's adsorption model.
\end{abstract}

Key words: PVA-silica hybrids, Sol-gel processing, Rhodamine 6 G, Adsorption, Sonohydrolysis

\section{INTRODUCTION}

Sol-gel synthesized silica materials have a long history and are extensively reviewed. ${ }^{1,2}$ There has been successful attempts to tailor the properties of the synthesized material by varying the precursors, synthesis conditions and process parameters like $\mathrm{pH}$, temperature, pressure and additives/templates. ${ }^{3-5}$ The overall process involves hydrolysis and polycondensation reactions of the organometallic (silicon alkoxides) or inorganic (silicic acid) compounds. Polymerization followed by condensation of siloxane bonds results in the formation of a gel which is described as a continuous solid frame work embedded in a large volume of fraction-liquid phase. Further processing results in the formation of dried gels which are named depending on the drying process i.e., aerogels (supercritical drying), xerogels (evaporative drying) and cryogels (freeze drying). Aerogels are known to have the highest surface area (above $1000 \mathrm{~m}^{2} / \mathrm{g}$ ) and are known as the lightest materials on earth. ${ }^{6}$

The pore structure and properties of the final products are strongly depending on the starting materials, the conditions of hydrolysis, aging, drying and the addition of modifiers. In recent years, the incorporation of organic polymers in the silica structure has resulted in the formation of organic-inorganic hybrids exhibiting interesting structural properties. ${ }^{7}$ The synthesis of inorganic-organic hybrids is mainly aimed to improve the structural properties of silica gels with respect to their brittleness, fragility, moisture sensitivity and homogeneity in porosity.

Polyvinyl alcohol (PVA) has been used by many research groups to modify the properties of silica aerogels,${ }^{8}$ xerogels, ${ }^{9}$ sonogels ${ }^{10}$ and in some cases even the presence of silica precursor was found to effect the properties of gels produced by PVA itself. ${ }^{11,12}$ Properties of gels produced by silica PVA hybrid sols are found to be modified mainly due to the hydrogen bonding between PVA and surface silanol groups during the sol-gel reaction. ${ }^{9,12}$ It is also found that the presence of PVA in the xerogel reduces its pore volume and surface area quite significantly due to the clogging of pores on silica surface with the bulky PVA molecules. ${ }^{9}$ This phenomenon can affect the catalytic properties of PVA modified silica gels. In this study, we have used PVA as a template for generating higher surface area xerogels by removing it through calcinations after the synthesis of the gels. The samples are found to have higher surface area than the gels synthesized without any PVA. The sorption properties of the gels are studied by using Rhodamine $6 \mathrm{G}(\mathrm{R} 6 \mathrm{G})$ as a model dye. R6G is one of the most popular fluorescent dyes and widely used to fabricate different luminescent materials. ${ }^{13}$ It can be used as the dye laser in solution (dissolved in water, eth- 
anol or methanol) or in solid state form (doped on sol-gel materials). Silica has been largely studied in last few years as an ideal sorbent for R6G. ${ }^{14-16}$ Our approach is to study the adsorption behaviour of R6G on our templated xerogels and analyze the effect of porosity of the gels on the adsorption process.

\section{MATERIALS AND METHODS}

\section{Reagents}

99\% pure TEOS and 98\% hydrolyzed PVA $(\mathrm{Mw}=75000)$ were purchased from Merck, $\mathrm{HCl}$ was purchased from Fluka and Ammonium Hydroxide from Fischer Scientific. Absolute Ethanol was purchased from Lab Scan. Rhodamine 6G was provided by Sigma. All the chemicals were used without further purification. Deionized water was used throughout the experiment.

\section{Experiment}

TEOS were slowly mixed with deionized water and $0.05 \mathrm{M} \mathrm{HCl}$ was slowly added to the mixture so that the $\mathrm{pH}$ reaches 2 . The molar ratio between TEOS, water and $\mathrm{HCl}$ was kept at 1:6:0.002. To obtain a homogeneous sol, the mixture was sono hydrolyzed with $30 \mathrm{kHz}$ ultrasonic radiation for two hours at room temperature. The mixture was distributed into 5 different vials and $1 \%$ aqueous solutions of PVA was slowly added to the homogenized sol in different proportions shown in Table 1. Afterwards $0.05 \mathrm{M}$ ammonium hydroxide was slowly added into each system with constant stirring so that $\mathrm{pH}$ reaches 5 . The gels started forming in all the systems when kept for 24 hours at ambient temperature and later at $50{ }^{\circ} \mathrm{C}$ for an hour. Later the solvent (water) was exchanged with Ethyl Alcohol for three days, exchanging the solvent after every 24 hours to strengthen the gel network. At the end of three days, the solvent was decanted and gels were allowed to dry slowly at $50{ }^{\circ} \mathrm{C}$ for 30 days.

The PVA template was removed through 2 hours calcination at $550{ }^{\circ} \mathrm{C}$ in a muffle furnace which heated the

Table 1. Surface Area of the xerogels with respect to their composition

\begin{tabular}{lcccc}
\hline Sample & $\begin{array}{c}\text { Compositions } \\
\text { (by volume) } \\
\text { TEOS mixture:PVA }\end{array}$ & $\begin{array}{c}\text { Surface Area } \\
\mathrm{S}_{\mathrm{A}} \\
\left(\mathrm{m}^{2} / \mathrm{g}\right)\end{array}$ & $\begin{array}{c}\text { Pore volume } \\
(\mathrm{cc} / \mathrm{g})\end{array}$ \\
\hline 1 & $\mathrm{SXG}_{1}$ & $20: 5$ & 4.265 & 0.985 \\
2 & $\mathrm{SXG}_{2}$ & $15: 10$ & 326.79 & 75.836 \\
3 & $\mathrm{SXG}_{3}$ & $10: 15$ & 402.205 & 92.723 \\
4 & $\mathrm{SXG}_{4}$ & $5: 20$ & 411.64 & 95.700 \\
5 & $\mathrm{SXG}_{0}$ & $25: 0$ & 353.544 & 81.538 \\
\hline
\end{tabular}

samples at a rate of $5^{\circ} \mathrm{C}$ per minute. The samples were ground through agate mortal and pestle and were further used for characterization.

\section{Sample Characterization}

The IR studies were carried out in absorbance mode with 28 scan per sample, using Thermo scientific Nicolet 6700 FTIR spectrophotometer in the range of 4000 to 400 $\mathrm{cm}^{-1}$. Thermal properties of the samples were analyzed in Mettler Toledo TGA/SDTA 851e at a temperature range of $0-1000{ }^{\circ} \mathrm{C}$ at a heating rate of $10{ }^{\circ} \mathrm{C}$ per minute. XRD spectrum was recorded using PANalytical X'Pert Pro diffractometer equipped with Nickel-filtered $\mathrm{Cu} \mathrm{K \alpha}$ radiations. Data was recorded using a step size of $0.04^{\circ}$, scan rate of 2 theta per second and a scan range between $0-80^{\circ}$ 2 theta. Tube voltage was $40 \mathrm{kV}$ and tube current was 30 $\mathrm{mA}$. Surface morphology of the gels was determined through a JSM-5910 Scanning Electron Microscope. For surface area analysis, data was collected on calcined samples that were degassed at $150{ }^{\circ} \mathrm{C}$ for 159 minutes. A Kelvin 1042 V 3.05 was used for the single point analysis of the calcined samples. The adsorptive gas used was Nitrogen while Helium was used as the carrier gas.

\section{Adsorption studies}

The adsorption experiments were carried out in the sonicator at room temperature for an optimum time of 40 minutes which based on preliminary experiments indicated as the sufficient period to achieve equilibrium. 20 additional minutes were given to the adsorption mixture, after switching off the ultrasonic waves, so that the adsorbent settles down at the bottom. To obtain the equilibrium adsorption curves, $10 \pm 1 \mathrm{mg}$ of the xerogel were mixed with $10 \mathrm{ml}$ of the dye solution of desired concentration i.e. $1,2.5,5,7.5,10,12.5 \mathrm{ppm}$. Dye concentration change was recorded by a UV-160A Shimadzu UV-Vis spectrophotometer (Shimadzu, Japan) with $1 \mathrm{~cm}$ path length, at the maximum wavelength of RG6 absorption (i.e. $530 \mathrm{~nm}$ ). The spectra of the dye solutions are taken before and after adsorption at room temperature and all the measurements were taken in triplicates.

\section{RESULTS AND DISCUSSION}

\section{Characterization}

Surface morphology: SEM studies show that the structure of xerogels is in the micrometer range and there is an irregular variation in a size ranging from 10 to 500 micrometers (Fig. 1). The structure of all xerogels is dense 


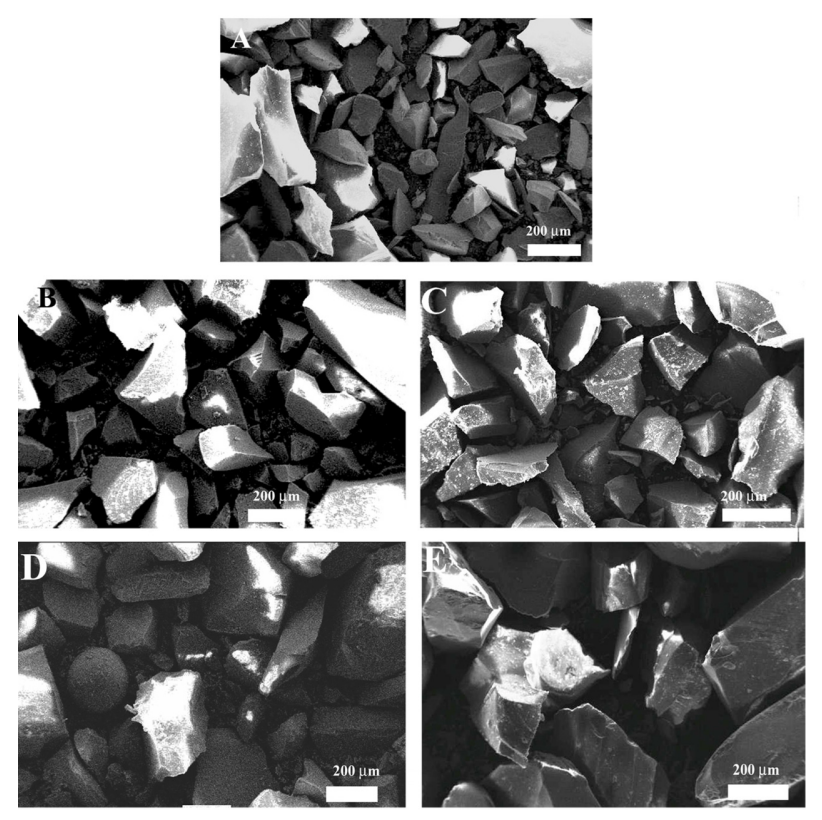

Fig. 1. SEM micrographs of (A) $\mathrm{SXG}_{0}$ (B) $\mathrm{SXG}_{1}$ (C) $\mathrm{SXG}_{2}$ (D) $\mathrm{SXG}_{3}(\mathrm{E}) \mathrm{SXG}_{4}$.

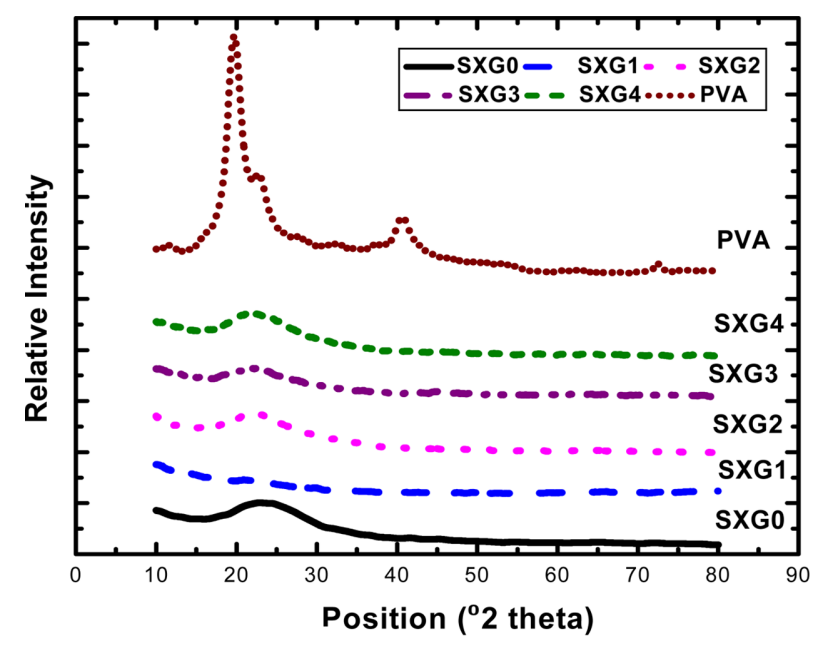

Fig. 2. XRD patterns of PVA and xerogels.

and non uniform and there seems no significant difference in the surface morphology of the silica particles with that of the templated silica which is strange as we were expecting smaller sized particles in case of templated silica. Similar phenomenon is studied by Rao et al..$^{17}$ and is justified on the basis of alkaline nature of the catalyst.

XRD studies: X-ray diffraction (XRD) has been widely used to study the crystalline nature of the substances. As shown in Fig. 2, XRD analysis of PVA shows crystallinity with two diffraction peaks at $11.4^{\circ}$ and $19.4^{\circ}$ corresponding to PVA crystalline peaks. ${ }^{18}$ While the XRD spectra of PVA templated silica and pure silica shows an

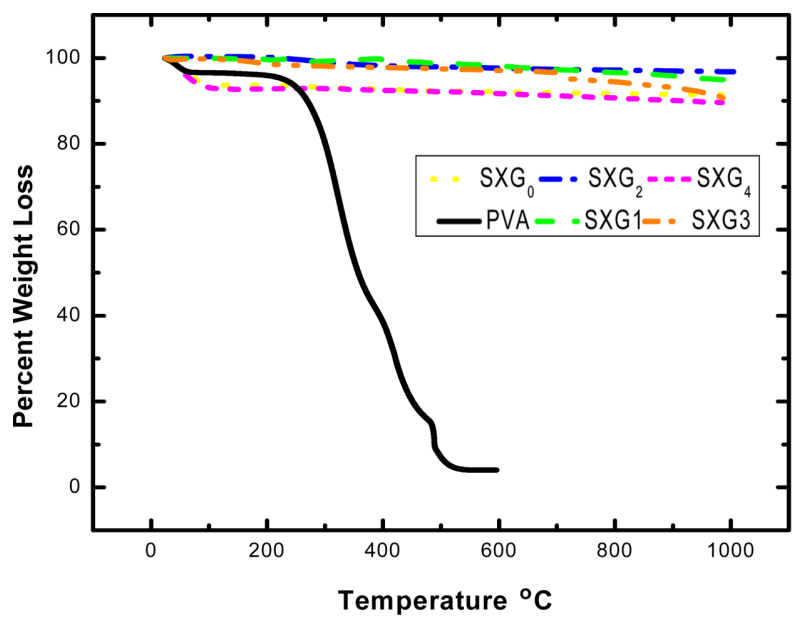

Fig. 3. TGA Thermograms of PVA, pure silica and PVA templated xerogels.

amorphous structure without any peak except a wide peak around $24^{\circ}$, which is a characteristic of the amorphous silica. ${ }^{19}$ Absence of typical crystalline peaks in the diffraction spectra of calcined xerogels is an indication of the removal of the template during the process of calcination.

TGA studies of the xerogels: TGA studies of the calcined gels further confirm complete removal of PVA from the gels as there is no significant thermal degradation in the gel till $900{ }^{\circ} \mathrm{C}$ while PVA degrades completely at $500^{\circ} \mathrm{C}$ (Fig. 3). A slight weight loss in some xerogels below $200{ }^{\circ} \mathrm{C}$ is mainly because of the loss of adsorbed water. Absence of a prominent weight loss in all the xerogels means complete removal of the PVA template, therefore the thermal behaviour of the xerogel prepared without any template and those prepared with templates show same trend in TGA curves.

FTIR behaviour of the xerogels: The main peak in the FTIR spectra of all the xerogels appeared is at $1090 \mathrm{~cm}^{-1}$ (Fig. 4) and is associated with the anti-symmetric stretching mode of Si-O-Si bonds in the $\mathrm{SiO}_{2}$ matrix. ${ }^{20}$ The bands at around $800 \mathrm{~cm}^{-1}$ and $460 \mathrm{~cm}^{-1}$ are respectively assigned to bond symmetric stretching and the bond rocking vibration of the Si-O-Si bonds in the three-dimensional $\mathrm{SiO}_{2}$ network. Pure PVA shows a very prominent peak at 3400 $\mathrm{cm}^{-1}$ because of its $\mathrm{OH}$ group ${ }^{21}$ and a minor one at around $1000 \mathrm{~cm}^{-1}$ which is because of the stretching movement of $\mathrm{C}-\mathrm{O}-\mathrm{H}$ in aliphatic alcohol. Interestingly both these peaks are missing in the PVA templated xerogels pointing towards the complete removal of $\mathrm{OH}$ group during the process of calcination.

Surface Area of the gels: Specific surface area $\left(\mathrm{S}_{\mathrm{A}}\right)$ of an adsorbent is a significant characteristic. It is the sum of 


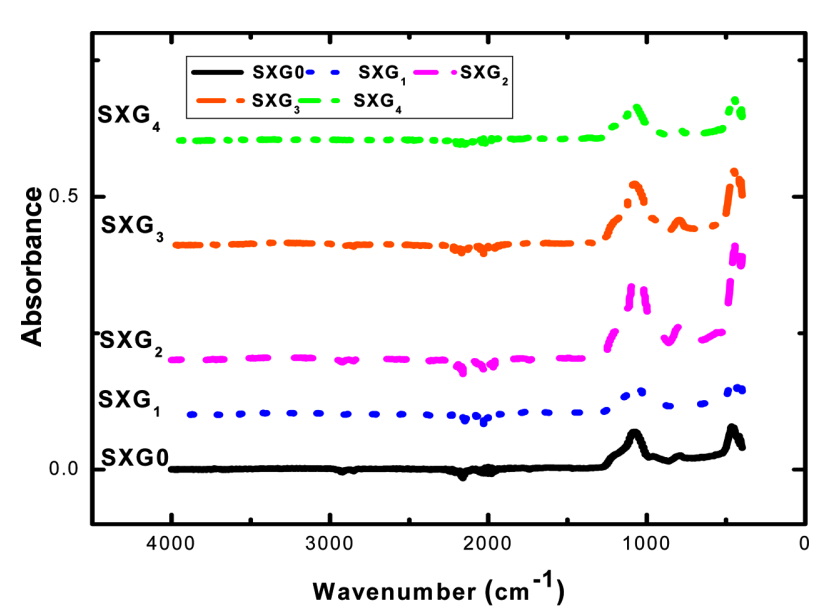

Fig. 4. FTIR spectra of PVA templated xerogels.

external and internal surfaces, i.e. the geometrical surface of the particles and the surface developed by the walls of the pores. As shown in Table 1, the surface area of PVA templated xerogels is generally found to be higher than that of the xerogels prepared without any PVA. Pore volume of the PVA templated gels (except $\mathrm{SXG}_{1}$ ) is also higher as compared to the gel prepared without any template. The surface area and pore volume seem to increase with the increase in PVA content of the gels which points towards the creation of pores inside the gel structure with the removal of the template. The higher the amount of the template, more spaces are created inside the gel structure. Surprisingly the difference in surface area and pore volume of the templated gels and the gel synthesized as a blank (without any template added) is not much pointing towards the possibility of incomplete removal of PVA from the gel and the rest is still residing within the gel. This strange phenomenon goes against all the other results especially XRD which shows an amorphous structure of

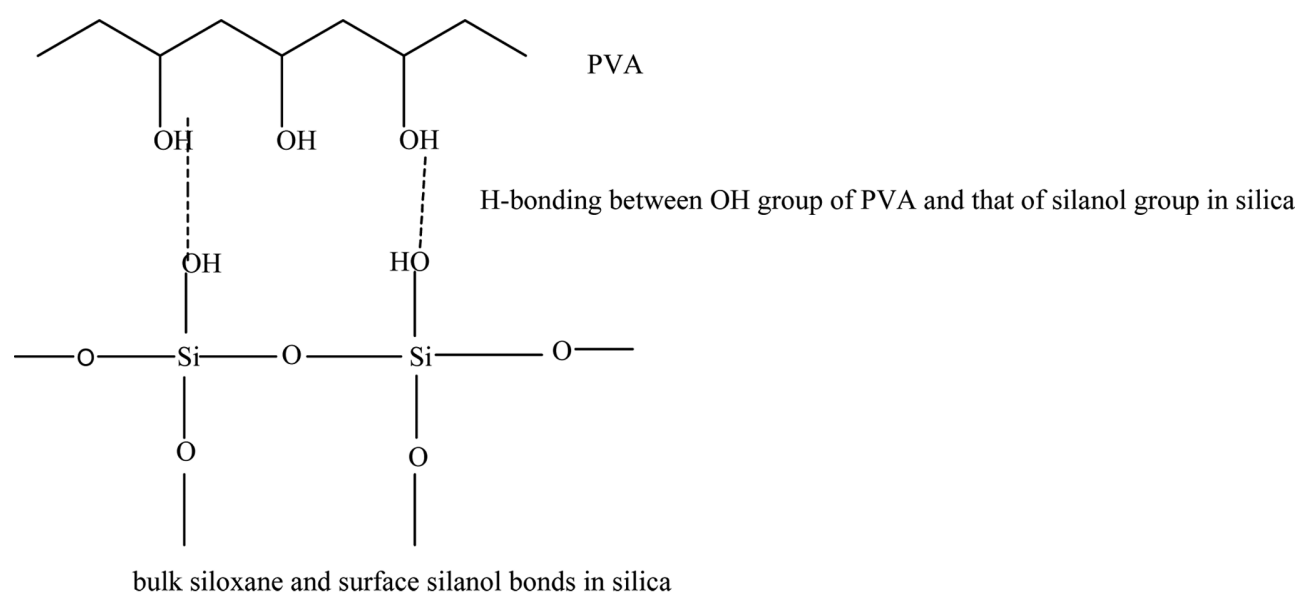

the xerogel and the FTIR spectra also are pointing towards the presence of silica in the gels. In fact, the PVA lying inside the gel does not seem to exist in a free state to show its crystalline nature and chemical structure properly. The -OH of the surface silanols of silica might have bound the -OH groups of PVA through some strong intermolecular bonds (Scheme 1) and has made it less mobile. This fact is supported by very low value of surface area and pore size of $\mathrm{SXG}_{1}$ in which PVA is 4 times lesser in volume than the silica precursor, therefore almost all the PVA might have trapped inside the gel structure producing even lesser pores than those in the blank sample $\left(\mathrm{SXG}_{0}\right)$.

\section{Adsorption Studies}

Adsorption studies of different solutions of R6G were conducted at an optimum time of 40 minutes. The amount of dye adsorbed onto the xerogel was calculated by a simple mass balance relationship:

$$
q=V\left(C_{0}-C\right) / m
$$

when $C_{e}$ is used instead of $C$ in Eq. (1), $q_{e}$ is obtained. $\mathrm{q}$ is the amount of dye up taken by the adsorbent $(\mathrm{mg} / \mathrm{g}$ ), $\mathrm{C}_{\mathrm{o}}$ is the initial dye concentration put in contact with the adsorbent $(\mathrm{mg} / \mathrm{L}), \mathrm{C}_{\mathrm{e}}$ is equilibrium dye concentration $(\mathrm{mg} / \mathrm{L})$ after the batch adsorption procedure, $\mathrm{m}$ is mass of adsorbent in $(\mathrm{g})$ and $\mathrm{V}$ is the volume of dye solution put in contact with the adsorbent. The Freundlich's isothermal model (equation 2) is the most convenient model which has been applied in many cases. ${ }^{22-24}$ It has the capacity to adopt the heterogeneous surface adsorption data. Mostly, the logarithmic form (equation 3 ) of the model is used to find out adsorption parameters.

$$
\begin{aligned}
& \mathrm{q}_{\mathrm{e}}=\mathrm{K}_{\mathrm{f}} \mathrm{C}_{\mathrm{e}}(1 / \mathrm{n}) \\
& \ln \mathrm{q}_{\mathrm{e}}=\ln \mathrm{K}_{\mathrm{f}}+(1 / \mathrm{n}) \ln \mathrm{C}_{\mathrm{e}}
\end{aligned}
$$



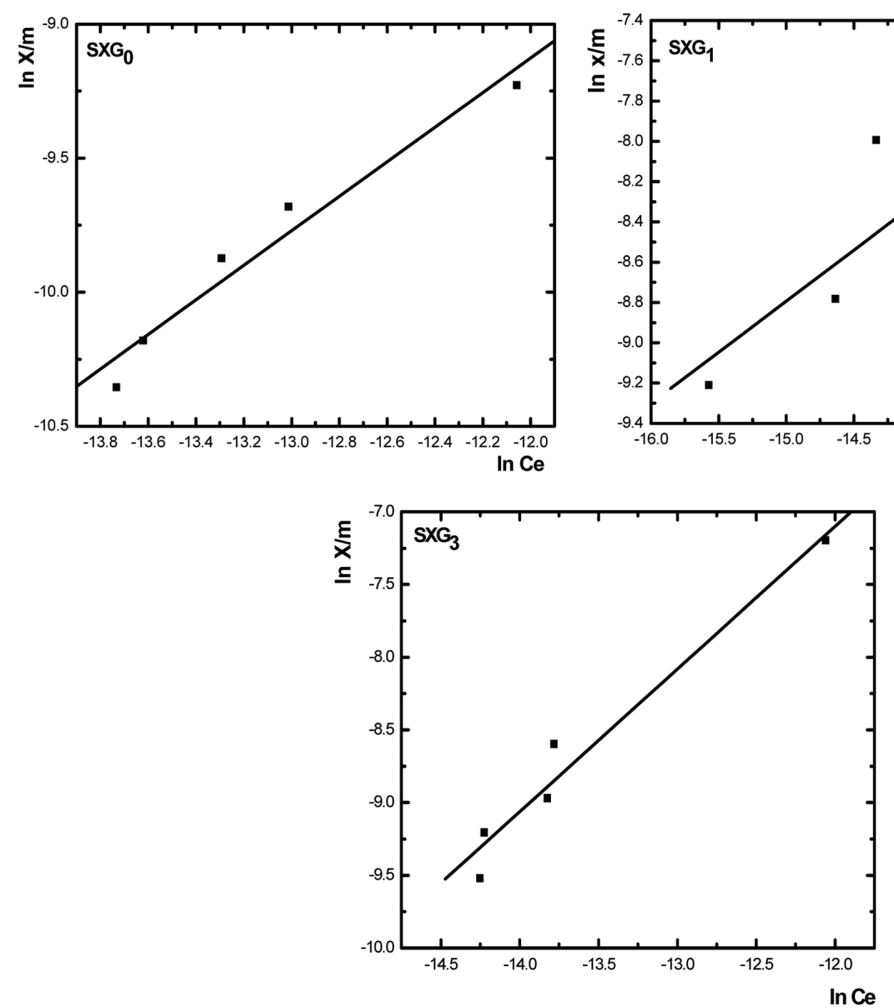
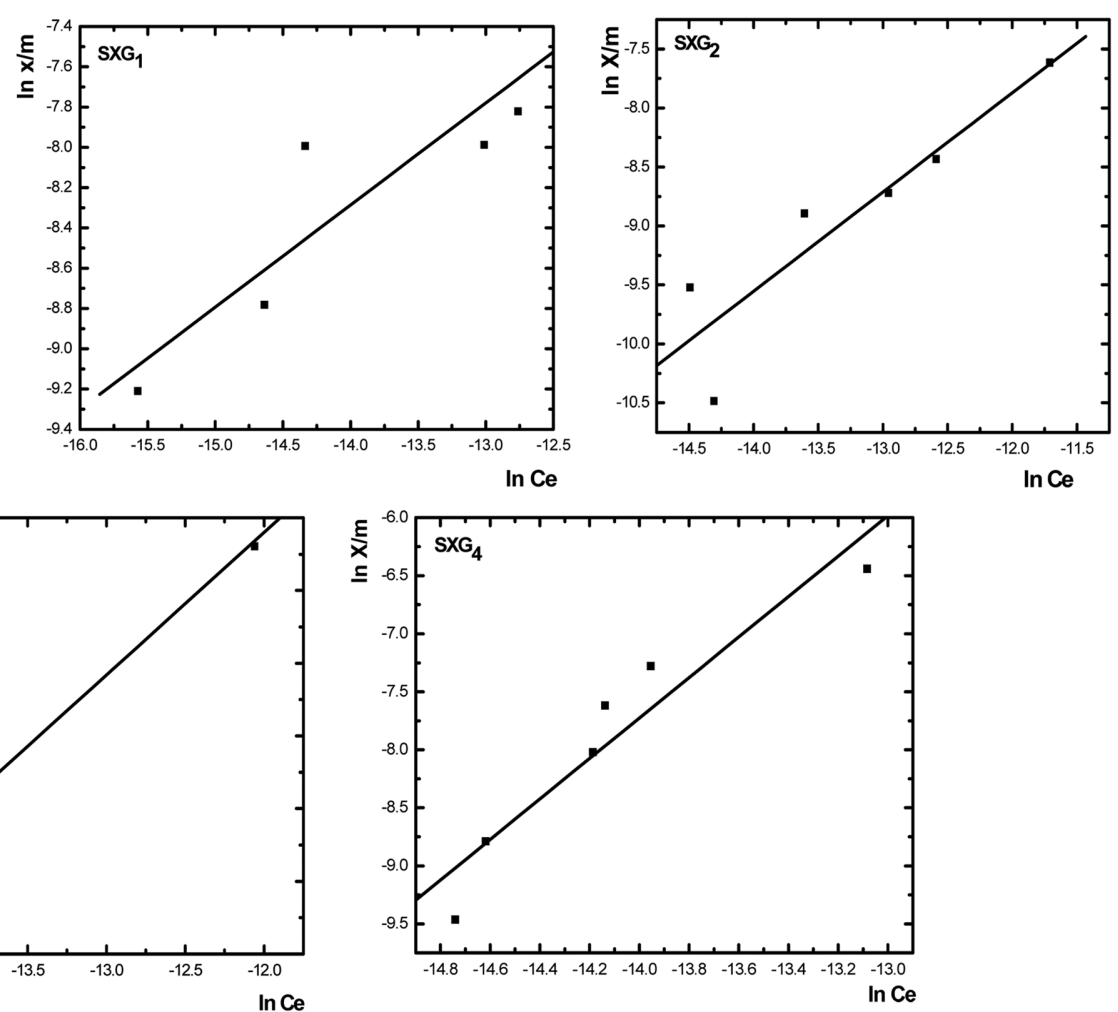

Fig. 5. Freundlich's isotherm for $\mathrm{SXG}_{0}, \mathrm{SXG}_{1}, \mathrm{SXG}_{2}, \mathrm{SXG}_{3}, \mathrm{SXG}_{4}$.

Generally $\mathrm{K}_{\mathrm{f}}$ and $1 / \mathrm{n}$ are the parameters which represent the factors that influence the adsorption of the adsorbate on the adsorbent. More specifically $\mathrm{K}_{\mathrm{f}}$ is interpreted in terms of adsorption capacity of the sorbent and $1 / n$ is considered as an indication of the heterogeneity of the surface and its capacity for the adsorbate. ${ }^{24}$ All the systems are observed to follow Freundlich's isotherm (Fig. 5) supporting the fact that the heterogeneous surface of the adsorbents is playing an active role during the adsorption process. Since Freundlich's isotherm assumes that several sites are involved with different adsorption energies, it can be applied to non ideal adsorption systems involving heterogeneous surfaces or multi layers. ${ }^{25,26}$

Increasing values of $\mathrm{K}_{\mathrm{f}}$ and $1 / \mathrm{n}$ with increasing template content (Table 2) explain the higher adsorption tendency of the templated gels directly proportional to the
PVA content i.e. an increase in the adsorption capacity with increasing PVA content. All gels except $\mathrm{SXG}_{1}$ show higher values of $1 / \mathrm{n}$ and $\mathrm{K}_{\mathrm{f}}$ in the same way as their surface area increases with increasing PVA content. Lower values of Freundlich's adsorption parameters for $\mathrm{SXG}_{1}$ are directly related to its lower surface area and pore volume (Table 1) which makes it less active for the adsorbate to land on and develop some interactions due to lack of active sites on its surface. Increased adsorption capacity of the gel templated by maximum PVA content proves the effect of high surface area on the adsorption process. It also supports the idea that successful removal of the template from the gel structure creates more space and active sites for the adsorbent greatly enhancing the adsorption capacity of the templated gels as compared to gels synthesized without any template.

Table 2. Freundlich's parameters

\begin{tabular}{cccccc}
\hline & Sample & Fitted Equation & $\mathrm{R}^{2}$ & $\mathrm{~K}_{\mathrm{f}}$ & $1 / \mathrm{n}$ \\
\hline 1 & $\mathrm{SXG}_{1}$ & $\mathrm{y}=0.5068 \mathrm{x}-1.191$ & 0.82265 & 0.3014 & 0.5068 \\
2 & $\mathrm{SXG}_{2}$ & $\mathrm{y}=0.841 \mathrm{x}+2.221$ & 0.8402 & 9.2173 & 0.8410 \\
3 & $\mathrm{SXG}_{3}$ & $\mathrm{y}=0.981 \mathrm{x}+4.676$ & 0.96283 & 126.868 & 0.9897 \\
4 & $\mathrm{SXG}_{4}$ & $\mathrm{y}=1.744 \mathrm{x}+16.693$ & 0.90548 & $1.77 \mathrm{E} 7$ & 1.7442 \\
5 & $\mathrm{SXG}_{0}$ & $\mathrm{y}=0.644 \mathrm{x}-1.393$ & 0.9568 & 0.2484 & 0.6444 \\
\hline
\end{tabular}




\section{CONCLUSION}

High surface area silica xerogels were synthesized by using PVA as template which is later removed through calcinations leaving behind spaces which resulted in the creation of porous surface quite suitable for heterogeneous adsorption. The removal of PVA was confirmed through FTIR, TGA and XRD analysis. Sonication was used firstly to hydrolyze gels and then to adsorb the dye solution so that the mixing and distribution of materials stays smooth and homogeneous. The high surface area xerogels can be used as adsorbents for Rhodamine $6 \mathrm{G}$ and it was found out that the templated gels provide active sites to the dye molecules to develop interactions which tightly hold the dye molecules on the silica surface. The adsorption process can be further studies and different conditions like $\mathrm{pH}$, temperature and concentration can be varied in future studies to develop a stable dye laser by doping dye solution with templated silica xerogels.

Acknowledgements. Higher Education Commission of Pakistan is acknowledged for providing financial support for this work.

\section{REFERENCES}

1. Maniar, P. D.; Navrotsky, A.; Rabinovich, E. M.; Ying, J. Y.; Benziger, J. B. J. Non-Crystalline Solids 1990, 124, 101.

2. Brinker, C. J.; Scherer, G. W. Sol-Gel Science: The Physics and Chemistry of Sol-Gel Processing; Academic Press: San Diego, 1990.

3. Brinker, C. J. Dunphy, D. R. Curr. Opin. Coll. Int. Sci. 2006, 11, 126.

4. Grandi, S.; Mustarelli, P.; Magistris, A.; Gallorini, M.; Rizzio, E. J. Non-Crystalline Solids 2002, 303, 208.
5. Mosquera, M. J.; de los Santos, D. M.; Valdez-Castro, L.; Esquivias, L. J. Non-Crystalline Solids 2008, 354, 645.

6. Fricke, J.; Tillotson, T. Thin Solid Films 1997, 297, 212.

7. Bandyopadhyay, A.; Sarkar, M. D.; Bhowmick, A. K. J. Mater. Sci. 2005, 40, 5233.

8. Rassy, H. El; Buisson, P.; Bouali, B.; Perrard, A.; Pierre, A. C. Langmuir 2003, 19, 358.

9. Awano, C. M.; Donatti, D. A.; Ibañez Ruiz, A.; Vollet, D.R. J. Non-Crystalline Solids 2009, 355, 1561.

10. Portella, J. A.; Donatti, D. A.; Ibanez Ruiz, A.; Vollet, D. R. J. Phys. Chem. C 2008, 112, 3552.

11. Mitsumata, T.; Hasegawa, C.; Kawada, H.; Kaneko, T.; Takimoto, J. React. Func. Polym. 2008, 68, 133.

12. Yano, S.; Iwata, K.; Kurita, K. Mater. Sci. Eng., C 1998, 6,75 .

13. Avnir, D.; Levy, D.; Reisfeld, R. J. Phys. Chem. 1984, 88, 5956.

14. Malfatti, L.; Kidchob, T.; Aiello, D.; Aiello, R.; Testa, F.; Innocenzi, P. J. Phys. Chem. C 2008, 112, 16225.

15. Rao, A. P.; Rao, A. V. Mater. Lett. 2003, 57, 3741.

16. Grandi, S.; Tomasi, C.; Mustarelli, P.; Clemente, F.; Carbonaro, C. M. J. Sol-Gel Sci. Technol. 2007, 41, 57.

17. Rao, A. V.; Bhagat, S. D. Solid State Sci. 2004, 6, 945.

18. Seoudia, R.; Abd El Mongyb, S.; Shabaka, A. A. Physica B 2008, 403, 1781.

19. Estella, J.; Echeverria, J. C.; Laguna, M.; Garrido, J. J. J. Non-Crystalline Solids 2007, 353, 286.

20. Innocenzi, P. J. Non-Crystalline Solids 2003, 316, 309.

21. Mansur, H. S.; Sadahira, C. M.; Souza, A. N.; Mansur, A. A. P. Mater. Sci. Eng., C 2008, 28(4), 539.

22. Walker, G. M.; Weatherley, L. R. Chem. Eng. J. 2001, 83, 201.

23. Li, H.; Xu, M.; Shi, Z.; He, B. J. Colloid Interface Sci. 2004, $271,47$.

24. Haghbeen, K.; Legge, R. L. Chem. Eng. J. 2009, 150, 1.

25. Reddad, Z.; Gerente, C.; Andres, Y.; Cloirec, P. L Environ. Sci. Technol. 2002, 36(9), 2067.

26. Yang, H.; Xu, R.; Xue, X.; Li, F.; Li, G. J. Hazard Mater. 2008, 152, 690 . 